\title{
Intervenção Mediacional na aprendizagem do Braille: um estudo com crianças deficientes visuais
}

\author{
Ana Maria Pereira Dionísio \\ Universidade Federal de Uberlândia - Uberlândia - MG - Brasil \\ Celia Vectore \\ Universidade Federal de Uberlândia - Uberlândia - MG - Brasil
}

\begin{abstract}
Resumo
O presente trabalho teve como objetivo construir e avaliar uma proposta de intervenção mediacional junto a crianças pré-escolares, por meio de oficinas de leitura e escrita no Sistema Braille. A proposta está fundamentada nos conceitos de Vigotski sobre a defectologia e na abordagem relativa à Experiência da Aprendizagem Mediada (EAM), desenvolvida por Feuerstein. A pesquisa foi desenvolvida por meio de dez oficinas mediacionais, nas quais se desenvolveu um trabalho com a leitura de uma história infantil e a partir dela atividades de leitura e de escrita no Sistema Braille. Participaram do estudo quatro crianças cegas, de seis e sete anos de uma instituição que atende pessoas com deficiência visual, na cidade de Uberaba/MG. Além das crianças, participaram também as mães e a professora responsável pela sala em que as crianças estudam. Consideramos que há necessidade de uma pesquisa mais aprofundada devido ao número reduzido de participantes.
\end{abstract}

Palavras-chave: Intervenção mediacional; deficiência visual; braille.

\section{Mediation intervention in braille learning: a study with visually impaired children}

\begin{abstract}
This study aimed to construct and evaluate a proposed mediational intervention with preschool children through reading workshops and writing in Braille system. The proposal is based on the concepts of Vygotsky on defectology and approach to the Mediated Learning Experience (MLE) developed by Feuerstein. The research was carried through ten Mediational workshops, in which they developed a work by reading a children's story and from her reading activities and writing in Braille system. The participants were four blind children of six and seven years in an institution that assists visually impaired people in the city of Uberaba / MG. Besides children also attended by the mothers and the teacher responsible for the room where the children study. We believe that there is need for further research due to the small number of participants.
\end{abstract}

Keywords: Mediational intervention; visually impaired; braille.

\section{Intervención de mediación en aprendizaje del braille: un estudio con niños deficientes visuales}

\begin{abstract}
Resumen
En el presente estudio se tuvo el objetivo construir y evaluar una propuesta de intervención de mediación junto a niños pre-escolares, por intermedio de talleres de lectura y escritura en el Sistema Braille. La propuesta está fundamentada en los conceptos de Vygotsky sobre la defectología y en el abordaje relativo a la Experiencia del Aprendizaje Mediada (EAM), desarrollada por Feuerstein. La investigación fue desarrollada por intermedio de diez talleres de mediaciones, en los cuales se desarrolló labor con la lectura de una historia infantil y a partir de ella actividades de lectura y de escritura en el Sistema Braille. Participaron del estudio cuatro niños ciegos, de seis y siete años de una institución que atiende personas con deficiencia visual, en la ciudad de Uberaba/MG. Además de los niños, participaron, también, las madres y la profesora responsable por la clase en que los niños estudian. Consideramos que hay necesidad de una investigación más profundizada debido al número reducido de participantes. Palabras clave: Intervención mediacional; deficiencia visual; braille.
\end{abstract}




\section{Introdução}

A deficiência visual priva a pessoa do mundo das imagens, sem as quais é necessário que outras rotas de compreensão do mundo sejam acessadas para que o desenvolvimento siga seu curso. Nesse sentido, o deficiente visual necessita de estímulos táteis e auditivos para se desenvolver, pois segundo Vygotsky (1997) a criança com alguma deficiência não é uma criança que apresente um desenvolvimento inferior ao das demais crianças, apenas se desenvolveu de outro modo.

Amiralian (1997) aponta que todo o processo de desenvolvimento da criança com deficiência visual está imerso numa cultura que expõe suas raízes e estas passam a fazer parte da constituição do ser humano. O nosso mundo é permeado pelas imagens que facilitam as interações, as relações, a linguagem e a aprendizagem. Para a pessoa que enxerga a absorção de informações escritas, icônicas ou simbólicas é imediata, ou seja, o cérebro tem o auxílio da visão, o que interfere diretamente na recepção, triagem e compreensão da situação que se apresenta por meio das imagens

Dentro dessa perspectiva, a criança vidente vai em direção ao objeto de seu interesse, explora e acaba por se apropriar dele numa atitude natural, que a visão Ihe permite no campo de ação. Já a criança cega tem a necessidade de uma mediação constante, por isso a realidade do ambiente circundante precisa lhe ser apresentada para que por meio da audição e do tato ela possa elaborar mapas mentais e rotas de compreensão do mundo e das pessoas a sua volta.

Nesse sentido, é desejável que para que essas rotas sejam exploradas haja o desenvolvimento de atividades significativas (Amiralian, 1997). Além disso, a exploração de objetos nos ambientes que Ihe são familiares, como a casa e a escola, são de fundamental importância, por serem ambientes conhecidos as oportunidades de construção de mapas mentais tornam-se mais suscetíveis de sucesso. Dentro desse contexto, destacamos a importância da família, como primeiro grupo social, que tem uma influência direta e importante no desenvolvimento da criança cega. Ou seja, os recursos internos criados no ambiente familiar deverão ser trabalhados e ampliados pela escola na educação formal.

Durante os primeiros três anos de vida as crianças desenvolvem seu contato com seu meio de origem, a família. Nesse contato ela adquire os fundamentos do desenvolvimento psicossocial. Segundo Vygotsky (1991), o controle postural e gestual deve estar automatizado antes que as funções superiores, como por exemplo, a linguagem, a memória, a vontade, o raciocínio lógico e a percepção estejam desenvolvidas.

Vigotski desenvolveu um estudo profundo relacionado ao contexto histórico-cultural que influencia diretamente a constituição da psique humana. Sua concepção era de que o homem biológico se transforma em homem sócio-histórico no qual a cultura é a parte essencial da constituição da natureza humana (Oliveira \& Bomtempo, 2009, p. 24).

De acordo com Luria (2006), um dos aspectos mais importantes da obra de Vigotski é o fato de que a pesquisa psicológica nunca deveria se limitar ao que ele chamava de especulação sofisticada e a modelos de laboratório, em que nada traduziam o mundo real. Para ele, os problemas da existência humana, tais como os sentidos na escola, no trabalho ou na clínica, serviam como contexto para os trabalhos nos quais Vigostski lutava para formular uma nova psicologia.

Vygotsky (1991) defendia que o desenvolvimento infantil é constituído por uma unidade dialética entre duas linhas genéticas - o desenvolvimento biológico e o cultural, sendo um processo único de formação biológico-social da personalidade da criança. No entanto, ele não o considera como uma simples junção do plano biológico e do social. $\mathrm{Na}$ sua concepção, o desenvolvimento cultural se sobrepõe aos processos de crescimento e maturação orgânica, pois a medida que o desenvolvimento orgânico se produz em um meio cultural, ele se torna um processo biológico sócio-historicamente condicionado.

Dessa forma, o desenvolvimento da criança está diretamente ligado aos processos reais da vida, que proporcionam diversas nuances e caminhos para que ela perceba o mundo a sua volta e possa desenvolver o que Vigotski denomina de funções psicológicas superiores.

Para Vygotsky (1991), o que nos diferencia dos demais animais é nossa capacidade de significação, que é a criação e o uso de signos, ou seja, de sinais artificiais. Assim, a utilização de signos nas crianças não é inventada ou ensinada pelos adultos, ela é uma série de transformações qualitativas, que a faz passar de um estágio ao outro dentro de um mesmo processo histórico.

Segundo Vygotsky (1991), as crianças são capazes de imitar um conjunto de ações que estão muito além de suas capacidades, isso pode ocorrer tanto com a orientação de adultos, como numa atividade coletiva. Para o autor, essa condição muda totalmente as considerações que eram feitas entre aprendizado e desenvolvimento em crianças, nas quais se consideravam que ela só aprendia devido ao seu desenvolvimento biológico ou inato.

A utilização do concreto nas atividades para crianças com deficiência, para Vygotsky (1991), deve ser vista como um apoio necessário e inevitável para o desenvolvimento do pensamento abstrato, ou seja, ele é um meio e não um fim em si mesma.

Em suas pesquisas sobre o desenvolvimento e a educação de pessoas com deficiência, Vygotsky (1997) baseia-se em três princípios: a crítica à análise quantitativa da deficiência, que mensurava os graus e níveis de incapacidade; o segundo, é o foco nas habilidades e capacidades de desenvolvimento e aprendizagem que as crianças com deficiência têm e não nas suas limitações e o terceiro que retrata a importância das interações sociais como forma de desenvolvimento das características biológicas. Nos escritos de Vigotski, a defectología considera que:

...qualquer defeito origina estímulos de compensação. Por isso o estudo dinâmico da criança que apresenta deficiências não pode limitar-se a determinação do grau e da gravidade 
da insuficiência, mas inclui indispensavelmente o controle dos processos de compensação, de substituição, processos edificadores e equilibradores no desenvolvimento e na conduta da criança. (Vygotsky, 1997, p. 14).

Dessa forma, consideramos que essa colocação vai ao encontro de nossa concepção com relação a aprendizagem da criança com deficiência visual, pois compactuamos com a afirmação de Vigostski (1997), de que a criança com alguma deficiência não é uma criança que apresente um desenvolvimento inferior ao das demais crianças, apenas se desenvolve de outro modo.

Segundo Vygotsky (1997), o funcionamento psíquico das pessoas com deficiência visual obedece às mesmas leis que regem o das demais pessoas, diferindo apenas em sua organização. Assim, é necessário conhecer esta forma de organização do pensamento para que se possa envolver a criança no aprender saudável, ou seja, aquele que cria situações imaginativas e criativas, que possibilitem o avanço em seu desenvolvimento, além de criar situações de interação.

Para Oliveira e Bomtempo (2009) a organização da realidade física que se verifica na criança com deficiência visual se realiza por meio da compensação de outros sentidos sensoriais. Assim, a compensação auditiva que se dá devido à perda visual precoce é extremamente funcional e possibilita suprir sua capacidade de autolocalização perceptiva e sua orientação espacial.

A cegueira cria uma nova e peculiar configuração na personalidade, origina novas forças, modifica as direções normais das funções, reestrutura e forma criativa e organicamente a psique do homem. Assim, a cegueira não é só um defeito, uma deficiência, uma debilidade, é também em certo sentido, uma fonte de revelação de atitudes, uma vantagem, uma força(por mais estranho e paradoxal que possa soar). (Vygotsky, 1997, p.99, Tradução nossa).

Entretanto, para que a aprendizagem se efetive é preciso acreditar no potencial da pessoa cega ou com baixa visão. De acordo com Feuerstein, Feuerstein e Falik (2010), a questão de acreditar que envolve a fé, a crença no potencial de desenvolvimento e capacidade de modificabilidade do aluno. Sua teoria da Modificabilidade Cognitiva Estrutural (MCE) tem como primeira premissa que todo ser humano é modificável. Baseado nos conceitos sócio interacionistas de Vigotski, Feurstein desenvolveu sua teoria a partir do trabalho com crianças e adolescentes sobreviventes do Holocausto. Para atender às necessidades deles, que tinham urgência de ter sua dignidade, moral e saúde física e psicológica resgatada, ele propôs uma abordagem baseada na modificabilidade cognitiva.

Em seu trabalho sobre a modificabilidade, Feuerstein e cols.(2010) ressaltam que esta habilidade permite ao indivíduo a aquisição de outras habilidades adicionais, que não estavam previamente presentes e acessíveis. Para eles as experiências de aprendizado diretas permitem que os alunos usem sua experiência acumulada para repetir outras ações bem sucedidas.

A modificabilidade, segundo Feuerstein e cols. (2010), envolve riscos, e em função disso indivíduo terá que aceitar e lidar com as situações em que pode não ser bem sucedido. Por isso, a Experiência de Aprendizagem Mediada (EAM) trata especifica e sistematicamente da resistência a situações em que o insucesso provoca o medo e a insegurança, para vencê-la.

Segundo Vectore (2010), a Experiência da Aprendizagem Mediada pode ser utilizada na sala de aula, por meio da compreensão do mediador acerca das reais necessidades de seus mediados, compatibilizando o "que deve ser ensinado, com o nível de compreensão dos mesmos e, simultaneamente, estar atento para conectar as experiências com eventos futuros." Portanto, longe de ser uma receita pronta e aplicável sem nenhum percalço ao longo do seu desenvolvimento, a EAM é um processo que exige do mediador esforço pessoal para a modificabilidade de si mesmo em busca de um trabalho no qual o foco é o mediado e suas possibilidades.

Para Fonseca (1996, p. 48), a modificabilidade “... refere-se às mudanças que se podem produzir no próprio indivíduo, na sua personalidade, na sua maneira de pensar e no seu nível global de adaptabilidade." Essa adaptabilidade é a capacidade do indivíduo de lidar com o que faz parte de sua realidade e que exigirá dele uma resposta positiva. Ao mesmo tempo, a modificabilidade está diretamente ligada à cognição representada pelos processos que levam o indivíduo a perceber (input), elaborar e comunicar (output) a informação, para se adaptar.

Feuerstein e cols.(2010) utilizam o conceito de Modificabilidade Cognitiva Estrutural (MCE), em substituição às concepções tradicionais de inteligência, para as quais é algo inato e imutável. Para eles a inteligência é uma força que direciona o organismo para se modificar e modificar a estrutura do pensamento e reação para responder às necessidades que aparecem.

O aspecto marcante da MCE é que ela depende da qualidade de intervenção do mediador, segundo Fonseca (1996), que deve criar formas de percepção, exploração e de isolamento de dados relevantes ou irrelevantes dentro dos novos processos e que produzam efeito no organismo do sujeito. Isso significa que, com base na estratégia da intervenção e de interação ela provoca a modificabilidade das estruturas cognitivas.

Feuerstein e cols.(2010) postulam que o indivíduo aprende com o mediador humano os objetos da natureza em si que não conseguem mediar com propósito e intenção. Por outro lado, o mediador humano é o transmissor de elementos culturais amplos e significativos dos objetos e eventos. Segundo o autor, esse é o grande desafio dos professores.

Dessa forma, a construção de significados deve ser trabalhada, de acordo com Feuerstein e cols. (2010), com a elaboração de valores e códigos culturais (linguagem). Já a mediação se dá quando se estabelece o uso adequado das palavras e a 
significação de símbolos e representações que são colocadas para o mediado, no caso o aluno. O mediador(professor) introduz problematizando, conceitos e significados, procedimento que colaborará para que o mediado(aluno) compreenda a realidade dada a partir de sua leitura de mundo, que por sua vez é elaborada por sentidos e significados que ele dá aos estímulos de sua realidade objetiva.

Acredita-se que é pela mediação que se atinge a modificabilidade e a diversidade, que, na opinião de Feuerstein, são os dois fenômenos mais propriamente humanos. A Teoria da Aprendizagem Mediada (EAM) é parte da Teoria da Modificabilidade Cognitiva Estrutural (MCE), já que a modificabilidade, condição essencial para a adaptação do indivíduo, depende da qualidade da mediação e dos processos cognitivos e afetivos deste.

De acordo com Kozulin (2000 citado por Gomes, 2002), os diversos instrumentos psicológicos, como a leitura, a escrita, as atividades numéricas, lógicas e simbólicas em geral devem ser bem mediados pelos professores. Se essa mediação for bem feita, os educandos se apropriam desses instrumentos e sofrem um processo de transformação que os levará a pensar de maneira diferente. Dentro desse contexto surge a perspectiva da Experiência de Aprendizagem Mediada (EAM) na intervenção mediacional na aprendizagem do Braille pela criança cega, baseada em cinco dos doze critérios de mediação de Feuerstein, denominados de universais, como:

1. Intencionalidade e Reciprocidade: O mediador procura meios e situações para facilitar a transmissão cultural e torná-la apropriada para cada aluno, que está recebendo a mediação, adequando-as às suas necessidades intrínsecas. A reciprocidade na interação é crucial, ao mesmo tempo em que a intencionalidade do mediador se constata por estruturar as situações; organizar os estímulos, manter a atmosfera de aprendizagem, preparar o material e provocar o interesse e a motivação pelos conteúdos.

2. Transcendência: A Experiência da Aprendizagem Mediada procura transcender o contexto imediato, o aqui-agora da situação em que a interação decorre, procurando atingir objetivos e necessidades mais longínquas e não meras satisfações imediatas, produzindo, consequentemente, o alargamento do sistema de necessidades do aluno.

3. Significação: A Experiência da Aprendizagem Mediada deve ser carregada de significação além da situação imediata, uma vez que a resolução da tarefa é uma resposta a uma necessidade criada.

4. Sentimento de competência: O objetivo é promover sentimentos de competência no aluno, reforçando e realçando o seu esforço de resolução de tarefas, condição essencial à modificabilidade cognitiva.

5. Regulação e controle do comportamento: Visa regular o comportamento, inibindo a impulsividade e ajustando o tempo de resposta do aluno. Regular a resposta em função das necessidades colocadas pela tarefa, é no fundo, produzir uma metacognição ${ }^{1}$ para integrar e elaborar, em

1 A metacognição diz respeito, entre outras coisas, ao conhecimento do próprio conhecimento, à avaliação, à regulação e à organização melhores condições, a informação necessária para programar e controlar a resposta adaptada.

\section{Método}

O objetivo geral deste trabalho foi propor e avaliar oficinas de intervenção mediacional na aprendizagem do Braille, que podem contribuir para o desenvolvimento da leitura e da escrita de crianças cegas em uma sala de Educação Infantil de uma Escola de Educação Especial de Uberaba, Minas Gerais.Essa necessidade se deu devido ao baixo desempenho das crianças na leitura e escrita do Braille. Esse desempenho foi constatado diante das observações feitas. Trata-se de uma pesquisa de abordagem qualitativa, que por meio do contato direto observamos os sujeitos utilizando como instrumentos de coleta de dados a observação participante com o objetivo de compreender a dinâmica de trabalho e interação em sala de aula. Além da observação participantes, foi utilizada a entrevista semiestruturada com as professoras e com as mães sobre a aprendizagem do Braille, as expectativas sobre a vida acadêmica, rotina e desenvolvimento das crianças. Com o intuito de elaborar uma análise mais detalhada optou-se pela gravação das dez oficinas. Participaram desse estudo quatro crianças cegas, com idade de seis a sete anos, sendo duas meninas e dois meninos.

\section{Procedimentos}

Após a autorização e a aprovação do Comitê de Ética em Pesquisa (CEP) da Universidade Federal de Uberlândia, foi realizado contato com a Instituição e a solicitação de permissão para a realização da coleta de dados nas dependências da instituição foi concedida pelo Termo de Consentimento Livre e Esclarecido (TCLE). Além da autorização da instituição também foram obtidas as autorizações dos pais/ responsáveis das crianças por meio da assinatura do TCLE, bem como da professora.

A primeira parte da construção de dados ocorreu por meio de uma observação participante, em dia e horário agendados previamente com a coordenadora e com as professoras. Nesse primeiro contato foi possível observar a dinâmica da sala, ou seja, a interação das crianças com as professoras e com a coordenadora responsável pela implantação do método Montessori para a educação infantil.

A intervenção com as crianças se deu no formato de oficinas, que foram planejadas pela pesquisadora, baseadas nos critérios de mediação de Feuerstein, de forma a trabaIhar por meio de uma história infantil a leitura e escrita no sistema Braille. A intervenção aconteceu nas dependências da Instituição. Foram organizadas 10 oficinas com cerca de 30a 40 minutos cada uma, uma vez por semana. As oficinas

dos próprios processos cognitivos. 
foram filmadas para posterior análise da atividade realizada. Após a análise as gravações foram descartadas.

\section{Entrevistas com as crianças, com as mães e com a professora sobre a leitura e escrita no sistema Braille}

Criança 1: É um menino de 6 anos com a doença de Norrie $^{2}$, que ocasiona a perda visual bilateral (sem percepção luminosa). No entanto, há resíduo visual que deve ser estimulado, mas ele não tem condição de ser alfabetizado em tinta, por isso será usuário do Sistema Braille de leitura e escrita.

Aparenta ser muito carinhoso, gosta de ouvir histórias, e tudo o que faz é com muita rapidez. Apesar de muito "elétrico" tem um ótimo relacionamento com as demais crianças da sala e devido a isso está sempre fazendo brincadeiras. Fala muito bem e já lê e escreve em Braille. Às vezes acha difícil escrever em Braille as palavras que não conhece. Não tem livros em Braille em casa para a leitura e a mãe lê os livros em tinta para ele. Teve contato com o Braille somente na instituição.

Gosta de animais, mas tem um certo medo de cachorros, pois já foi atacado por um. Adora fazer natação, usar o computador e também gosta muito dos momentos de lazer na escola. Está aprendendo teclado. Nas oficinas presta muita atenção às histórias e nas atividades. Quer fazer tudo depressa.

Criança 2: É uma menina de 6 anos, não tem laudo médico quanto a patologia e o motivo da perda da visão, mas usa prótese (olho de vidro) nos dois olhos e será usuária do Sistema de Leitura e Escrita Braille.

Demonstra ser muito esperta, amiga e prestativa. Ela tem um ótimo relacionamento com os colegas, principalmente com a outra menina(Criança 3) da sala. Sempre está disposta a ajudá-la. Tem uma excelente comunicação, pois consegue expressar sua opinião e suas vontades com muita convicção. Gosta de ouvir histórias e de aprender coisas novas. A cada conquista em termos de aprendizado se sente mais segura. Tem uma excelente orientação e mobilidade, que foi desenvolvida na instituição e também com a família. Sua mais recente conquista foi conseguir andar de bicicleta sem rodinhas. Possui excelente coordenação motora fina e grossa o que tem lhe ajudado bastante no aprendizado do Sistema Braille. Nas oficinas demonstra muito interesse pelas histórias e é muito detalhista e observadora.

A criança lê e escreve em Braille e, acha difícil quando não leu uma palavra e tem que escrevê-la. Seu contato com o Braille aconteceu, quando entrou para a escola da instituição.

Criança 3: É uma menina, tem 6 anos e é cega total devido a uma retinopatia diabética associada a um defeito nas vias ópticas. Não tem resíduo visual. Será usuária do

2 Doença caracterizada por displasia retiniana hereditária que se manifesta com duplo descolamento congênito da retina de caráter hemorrágico, associado a atraso mental e surdez.
Sistema de Leitura e Escrita Braille. Aparenta ser muito esperta e inteligente, tem ótima comunicação, oralidade, facilidade em aprender tudo que o professor fala, porém a coordenação motora e expressão corporal da aluna não permitem que ela realize as atividades com destreza. Para o desenvolvimento dessas habilidades faz acompanhamento com a professora de Orientação e Mobilidade, o que tem contribuído bastante para sua locomoção, marcha e mapa mental $^{3}$. No relacionamento com os demais alunos da sala ela é muito carinhosa, atenciosa e prestativa. Gosta de dançar, cantar e também gosta muito de animais, principalmente cachorros. Nas oficinas ela demonstra muito apreço pelos colegas e faz questão de estar sempre junto com algum deles quando os quadros sobre a história são mostrados. Além disso, tem um conhecimento de mundo muito bom e consegue fazer associações durante a leitura com algo que já viu.

Ela acha que escrever e ler em Braille é difícil, já que ela não conhece as palavras. Em casa a mãe lê histórias para ela, mas os livros são em tinta.

Criança 4: É um menino de 7 anos com Glaucoma congênito. Passou por cirurgias nas $1^{\mathrm{a}}$ e $3^{\mathrm{a}}$ semanas de vida. Tem percepção de luz no olho direito, mas não no esquerdo. Usa medicação tópica para hidratação dos olhos. É cego e será usuário do Sistema de leitura e escrita Braille.

$\mathrm{O}$ aluno demonstra ser esperto e com bom potencial cognitivo: faz cálculos mentais de adição e subtração, sabe "oralmente" o alfabeto Braille, porém não consegue transferir o alfabeto Braille para a reglete. Apesar de nunca ter frequentado outra escola, tem muito conhecimento de mundo e informações que as outras crianças não possuem.

Demonstra ser uma criança introspectiva e calada. Não aceitou fazer a sondagem quando foi proposta. Durante a primeira oficina ficou em silêncio o tempo todo. $\mathrm{Na}$ segunda oficina me aproximei dele e estimulava sua participação. Aos poucos foi se soltando e nas demais se mostrou bem participativo, interessado e muito carinhoso também. Tem uma memória que se destaca, quando comparada às demais crianças participantes, tanto para relato de fatos, bem como para área da matemática. Gosta muito de usar o computador e de jogar baralho (em Braille) com a avó e com, outro colega que também é cego.

Ele não gosta de escrever nem ler em Braille, diz que já sabe muita coisa. Em casa a mãe lê para ele, mas os livros estão em tinta.

\section{Professoras}

Atuam na sala duas professoras que foram cedidas pela Prefeitura Municipal de Uberaba, por meio do convênio com a instituição. As duas são formadas em Pedagogia,

3 Um mapa mental é um diagrama que se elabora para representar ideias, tarefas ou outros conceitos que se encontram relacionados com uma palavra-chave ou uma ideia central. A sua principal função é geração, visualização e classificação das ideias, o que colabora para o estudo, a organização de informações, a tomada de decisões e a escrita. 
passaram por um treinamento para utilização do material Montessori e adquiriram os livros para a elaboração das atividades em sala.

A professora entrevistada foi a que tem mais tempo na sala e conhece as crianças, pois a outra é recém admitida na escola da instituição. Ela tem 42 anos, é casada e atua como docente há cerca de 10 anos.

De acordo com a professora, por terem os alunos perfis muito diferentes, as atividades propostas devem considerar a individualidade de cada um, bem como a sua patologia. Assim, as atividades propostas de alfabetização que acontecem no momento de trabalho pessoal (antes do lanche) são diversificadas, atendendo a preferência e escolha de cada criança, como: trabalho com material Montessori e Braille ou colorir, pesquisar em revistas, recortar ou ficar com seus objetos coloridos, plástico, rodando e lambendo, ouvir música e assistir histórias e ouvindo músicas no computador (no caso o aluno autista) ou fazer atividades sensoriais e de vida prática ou ainda, fazer mais atividades voltadas para matemática.

$\mathrm{Na}$ hora de brincar, que sempre acontece após o lanche, alguns formam grupos e brincam juntos, o aluno que é autista não interage com os colegas, outro prefere brincar só. No entanto, todos demonstram gostar de pular na cama elástica. A professora salientou que sempre tem o cuidado de propor atividades que proporcionem a socialização, mas ao mesmo tempo, que respeite a individualidade de cada um.

Os interesses são bem variados, todos demonstram gostar de ouvir histórias, ouvir músicas, brincar na brinquedoteca, ir para a Biblioteca, explorar o pátio da escola, ouvir histórias em ambientes diversos (próximo ao pé de jabuticaba, no pátio da escola, na biblioteca). Além disso, as aulas de musicalização e de natação despontam como as preferidas pelas crianças.

Quanto ao material Montessori, ele é relevante no aspecto da vida prática e também na estimulação sensorial, colaborando para a independência e concentração. Segundo a professora, esses aspectos colaboram na aprendizagem do Sistema de Leitura e Escrita Braille.

Os textos utilizados em sala não são preparados por ela e sim pela supervisora, que pesquisa e entrega já impresso em Braille para a atividade com as crianças. Não há uma sequência de temas geradores trabalhados, os textos e as atividades de escrita são escolhidos aleatoriamente. Segundo a professora, os alunos têm um bom conhecimento do Braille, mas que ainda precisa ser desenvolvido.

\section{Mães}

Mãe da Criança 1: Ela é dona de casa e é quem cuida do menino. Demonstra ser receptiva e também presente na vida da criança. $O$ casal descobriu a deficiência quando o menino tinha dois meses e os atendimentos na instituição (estimulação visual, terapia ocupacional e estimulação sensorial) tiveram início quando ele tinha seis meses. O desenvolvimento foi normal com amamentação até os cinco meses, sentou com seis meses, com onze falou sua primeira palavra e andou com um ano. Sempre foi uma criança muito agitada e nervosa, mas quando entrou na escola e passou a ter uma rotina fora de casa ele melhorou muito. Ele se alimenta e toma banho sozinho. Se tem fome procura o que comer, se tem sede procura água ou suco. Usa o computador sozinho, mas ainda precisa de ajuda para se trocar e escovar os dentes.

Quando souberam da patologia e suas consequências foi um susto para a família, mas hoje ela encara como uma coisa normal. Procuram estimulá-lo no ambiente familiar trazendo recursos como um relógio que diz as horas, o computador tem o recurso do programa de voz e outros objetos que contribuam para o desenvolvimento dele. A mãe ressaltou que a deficiência visual é algo normal para ela, pois tem um irmão que também é deficiente visual.

Quanto ao hábito de leitura, tanto ela quanto o marido leem para o menino, pois ele mesmo pede. Na família, só ela e sua mãe sabem o Braille, porque fizeram o curso oferecido pela instituição; o marido e a sogra estão aprendendo.

Mãe da criança 2: Trata-se de uma dona de casa e é quem cuida da menina. Mostrou-se uma pessoa muito receptiva a entrevista e também ao trabalho que seria desenvolvido com as crianças. Segundo ela, não foi fácil receber a notícia de que a filha não enxergaria. Cada conquista da menina é também uma conquista para ela, sendo que a última conquista foi andar de bicicleta sem rodinha. Hoje em dia, tanto ela quanto o marido consideram a cegueira da filha como uma coisa normal, principalmente pelo fato de ela fazer de tudo. Se preocupam para que seja cuidada da forma mais comum que existe, para não correr o risco de ela ser mais uma cega sem informação nesse mundo. $\mathrm{Na}$ sua opinião, é preciso paciência e persistência para que a criança cega se desenvolva e isso ela tem de sobra, pois quer que a filha se torne uma grande mulher.

A menina gosta muito de histórias e adora a escola. Para ajudá-la, a mãe fez o curso de Braille e o pai também está aprendendo. Ela quer que a filha se torne independente, que tenha uma profissão, se case e tenha filhos, por isso ela a acompanha e procura fazer o que é necessário para que isso aconteça e a criança seja feliz.

Mãe da criança 3: Trata-se de dona de casa e é quem cuida da menina. Durante a entrevista se mostrou bem reservada e sem muita vontade de responder de maneira mais abrangente as perguntas. Segundo ela, a gravidez foi normal, mas foi um susto muito grande ao saber da deficiência. Ela ainda tem dificuldade de permitir que a menina faça as coisas, com medo de que ela se machuque.

A menina é bem tranquila, em casa gosta de brincar e assistir televisão, adora desenhos. Mas para tudo ela chama a mãe e ainda precisa de ajuda para se vestir, tomar banho, escovar os dentes etc.

A mãe fez o curso de Braille na instituição para poder acompanhar o desenvolvimento e as tarefas da escola. Quanto à leitura, ela só lê quando as professoras enviam algum livro para casa, mas nem todos estão em Braille. A menina solicita que ela leia todas as noites e, muitas vezes, pede para repetir a mesma história 
Ela espera que a menina se desenvolva e possa cursar uma faculdade, casar e ter uma família, bem como um trabalho que permita que ela se sustente. Mãe da criança 4: Trata-se de uma dona de casa e de todas, é a mais jovem. Apesar de sorridente e receptiva foi muito reticente nas respostas. A sua gravidez foi normal e o desenvolvimento do menino também. É ela quem cuida dele e que o acompanha nas atividades da escola e nos atendimentos no ICBC.

Quanto à deficiência, ela considera como uma coisa normal, pois na família o sogro, a sogra e duas tias são cegos. O convívio com a família é muito harmonioso e todos colaboram para o desenvolvimento do menino conscientes das suas limitações.

Eles têm muitos livros, pois ela gosta muito de ler e sempre lê para ele. Na família todos conhecem e sabem o Braille. Considera a Instituição muito boa, gosta muito do trabalho das professoras, mas acredita que deveria haver um trabalho mais abrangente, com história, ciências, geografia, português etc., favorecendo o desenvolvimento das crianças.

\section{Observação da dinâmica do trabalho em sala}

A sala é muito bem equipada e organizada com todo material Montessori para a Educação Infantil. Nenhum material original da linha Montessori foi adaptado para as crianças cegas, bem como não há nenhuma inscrição em Braille nos móveis ou nos materiais, apenas um alfabeto elaborado pelas professoras fixado na parede.

Por se tratar de uma Escola de Educação Especial, a sala de Educação Infantil também tem alunos de primeiro ano do Ensino Fundamental. São oito alunos no total, sendo que quatro crianças são cegas e quatro com baixa visão, a faixa etária fica entre quatro e seis anos. Das oito crianças matriculadas na sala, três têm algum outro comprometimento (físico e/ou intelectual) associado à deficiência visual.

O horário das aulas é das 13:00h às 17:00h, de segunda à sexta. A rotina começa com a chegada da Van que traz as crianças. São recepcionadas no portão da instituição pelas professoras, que as conduzem até a sala. Quando entram na sala deixam os materiais no lugar reservado e iniciam a aula cantando o Hino Nacional. Após o hino, cada criança deverá escolher cinco materiais da linha Montessori para trabalhar.

Uma a uma, as crianças pegam os tapetes para sentar no chão e escolhem o primeiro material, a escolha e a sequência do trabalho é livre. Outro aspecto do trabalho é que ele é sempre realizado individualmente, ou seja, não há interação entre as crianças, apenas a supervisão das professoras. Além disso, todo o trabalho, que para as crianças cegas se resume ao toque, encaixe e nomeação das peças é realizado em silêncio. A atividade é considerada finalizada após a criança manipular cinco tipos diferentes de materiais e guardá-los.

Na sequência as crianças são separadas, as com baixa visão vão para o trabalho de alfabetização em tinta com uma das professoras e as cegas para o trabalho com o sistema Braille. Aquelas que ainda não aprenderam o Braille ou não foram alfabetizadas em tinta, desenvolvem outras ativi- dades lúdicas. As atividades em Braille são realizadas na sala com a Professora e envolvem a leitura de pequenos trechos, ditados de palavras e frases. Os textos são elaborados pela supervisora e impressos em Braille. Segundo a professora, às vezes as crianças levam livros e textos para ler em casa.

Toda essa dinâmica ocorre antes do horário do lanche, que acontece às 15:30, pois a coordenadora não permite interrupções para evitar que as crianças dispersem a atenção. Após o intervalo, algumas passam por atendimentos de apoio: terapia ocupacional, fisioterapia, estimulação visual (baixa visão), hidroterapia, orientação e mobilidade, etc. Por volta das 16:45, a Van chega para levar as crianças para casa. Cada uma recolhe o seu material, pega sua mochila e todas são acompanhadas pelas professoras até o portão da instituição.

Dentro dessa dinâmica há aspectos interessantes a serem ressaltados. O primeiro é a forma como as crianças cegas se movimentam na sala. Totalmente à vontade e com uma excelente noção espacial da localização dos materiais, assim como os espaços externos da sala. Outro aspecto interessante é que elas reconhecem as pessoas pela voz e percebem quando alguém diferente entra na sala.

\section{Sondagem da leitura e escrita das crianças na etapa inicial do trabalho}

A sondagem foi utilizada como uma estratégia para identificar o conhecimento das crianças acerca do sistema Braille, sendo realizada na própria sala das crianças, mas individualmente. A partir dos resultados apresentados, as atividades de leitura e escrita foram elaboradas ou adaptadas. A sondagem constou da escrita do nome e de um ditado de palavras de duas categorias semânticas (frutas e animais), para serem escritas em Braille. A leitura foi avaliada por sentenças simples que envolveram o nome delas e dos colegas da sala, com palavras usadas no dia a dia e, por último, uma parlenda simples. A partir desse trabalho inicial, constatou-se que as crianças de maneira geral, não têm fluência na leitura em Braille, sendo esta fragmentada, sem apresentar uma relação com o significado das palavras.

\section{Atividades realizadas com as crianças durante as oficinas}

Primeira oficina: duração 40 minutos. No início foi apresentada a proposta do trabalho para as crianças e, em seguida, se deu a leitura do livro E o dente ainda doía, de Ana Terra.

Segunda oficina: duração 40 minutos. Continuação da leitura do livro E o dente ainda doía, de Ana Terra.

Terceira Oficina: duração 35 minutos. A terceira oficina teve por objetivo a retomada da história por meio de perguntas, para saber se as crianças compreenderam a leitura. Num segundo momento, foi feita leitura de palavras do texto com três categorias, sendo animais, números e objetos. Ao final, 
Tabela 1. Comportamento da pesquisadora segundo os critérios de mediação.

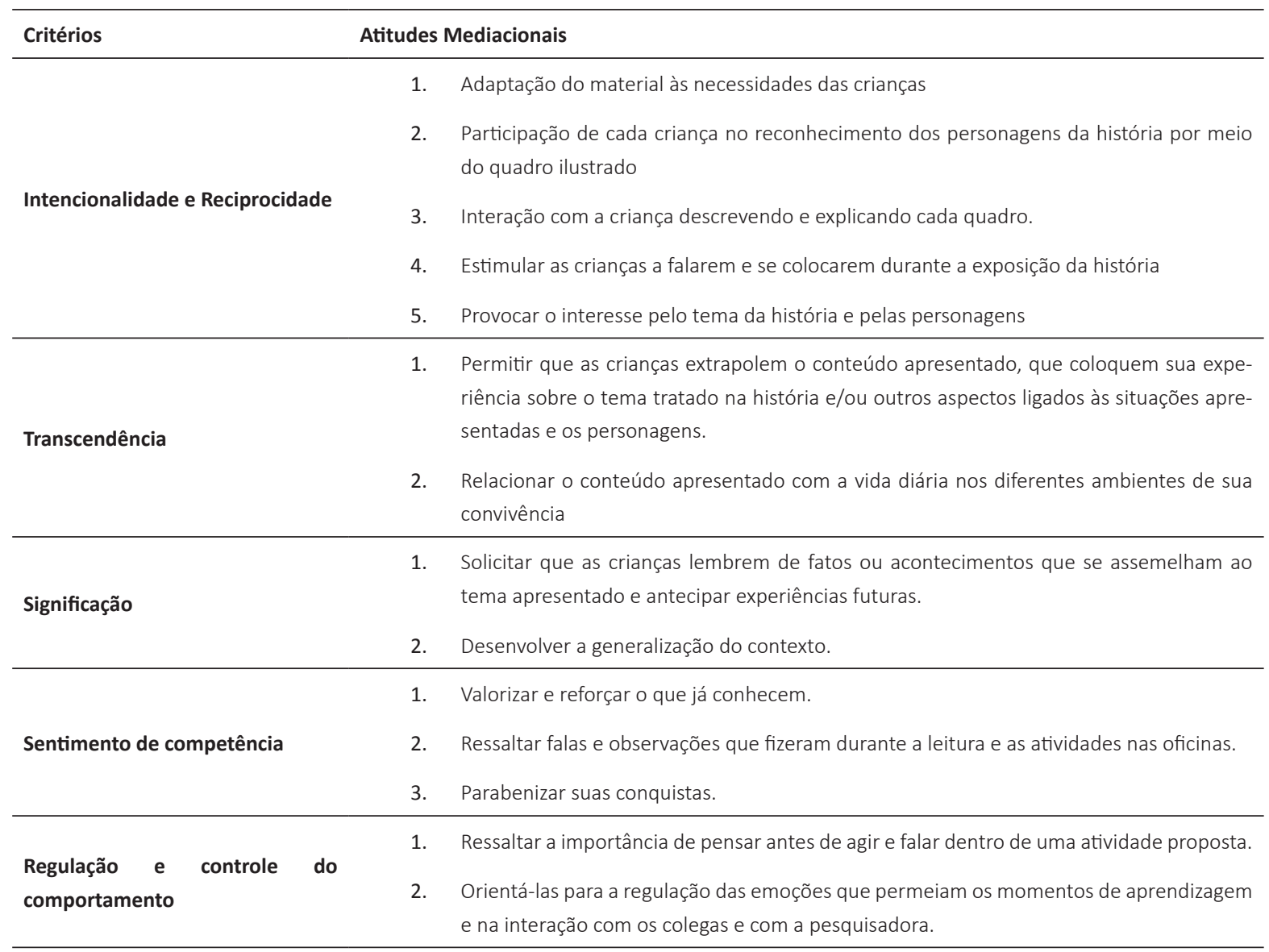

foi entregue para cada aluno uma cópia do livro em Braille e em tinta (para os pais), para que eles pudessem ler em casa.

Quarta oficina: duração 35 minutos. Nessa oficina foi proposto um jogo de leitura com trechos da história, que deveriam ser escolhidos e lidos pelas crianças. Após a escoIha do trecho, ele foi ditado pela pesquisadora; cada criança organizou a sua reglete para fazer a atividade.

Quinta oficina: duração 40 minutos. O objetivo dessa oficina foi a organização, pelas crianças, da sequência da história, a partir da leitura de fichas com os trechos por elas escolhidos. Todas as fichas estavam escritas em Braille. Além disso, foi solicitado uma tarefa para casa, que consistia em escrever em Braille algo sobre um dos personagens do livro para ser discutido no próximo encontro.

Sexta Oficina: duração 40 minutos. A oficina iniciou com a leitura dos textos produzidos em casa pelas crianças, cada criança leu o que escreveu sobre o livro. A partir da leitura começamos a discutir o que havia de semelhante e de diferente que cada uma escreveu. Ao final cada criança deveria escolher um colega e escrever o que achou da história por ele escrita, parabenizando-o (a) pela sua produção.
Sétima oficina: duração 40 minutos. O objetivo dessa oficina foi trabalhar o vocabulário do livro, por meio do jogo de Bingo.

Oitava oficina: duração 40 minutos. Após o trabalho com a leitura do texto e escrita por parte das crianças e também os jogos, essa oficina teve como objetivo a ampliação dos conhecimentos sobre os animais que apareceram no texto, acrescido da leitura das informações pelas crianças.

Nona oficina: duração 40 minutos. Cada criança escolheu um animal da história e Ihes foi entregue a ilustração para que fizessem a descrição do animal por escrito e lessem para a turma.

Décima Oficina: duração 40 minutos. Essa oficina teve como objetivo realizar uma atividade final do trabalho para avaliar a evolução das crianças na leitura e na escrita Braille. A atividade consistiu em um resumo da história para a leitura e um ditado de um trecho que a criança sorteava na hora.

A seguir sintetizamos os dados antes e depois das oficinas na tabela 2 , 
Tabela 2. Alterações observadas nos comportamentos das crianças nas oficinas.

\begin{tabular}{|c|c|c|}
\hline Criança & $\begin{array}{l}\text { Comportamento da criança antes } \\
\text { das oficinas }\end{array}$ & Comportamento após as oficinas \\
\hline Criança 1 & $\begin{array}{l}\text { Carinhoso e com bom relaciona- } \\
\text { mento com as demais crianças. } \\
\text { Muito ativo e gosta de fazer as } \\
\text { coisas muito rápido. }\end{array}$ & $\begin{array}{l}\text { Realiza as tarefas com mais calma e demonstrou avanços na } \\
\text { leitura com maior fluência e significação e na escrita sem os } \\
\text { erros apresentados na sondagem inicial }\end{array}$ \\
\hline Criança 2 & $\begin{array}{l}\text { Esperta, amiga e prestativa. Ótimo } \\
\text { relacionamento com os colegas. De- } \\
\text { terminada e organizada. }\end{array}$ & $\begin{array}{l}\text { Demonstrou avanços com a leitura mais fluente e com signi- } \\
\text { ficação e na escrita sem tantos erros no Sistema Braille, bem } \\
\text { como um senso de determinação mais apurado pelas conquis- } \\
\text { tas realizadas na leitura e na escrita. }\end{array}$ \\
\hline Criança 3 & $\begin{array}{l}\text { Esperta e inteligente, tem ótima co- } \\
\text { municação, mas ainda apresenta } \\
\text { uma coordenação motora pouco de- } \\
\text { senvolvida. Insegura. }\end{array}$ & $\begin{array}{l}\text { Demonstrou maior segurança na realização das atividades e } \\
\text { um conhecimento de mundo muito acima do demonstrado pela } \\
\text { maioria das crianças. A coordenação motora também demons- } \\
\text { trou avanços, pois não se sentia mais insegura em realizar as } \\
\text { atividades. Ainda demonstrou alguns enganos na utilização do } \\
\text { sistema Braille, mas em menor grau em relação a sondagem e } \\
\text { maior fluência na leitura }\end{array}$ \\
\hline Criança 4 & $\begin{array}{l}\text { Inteligente, introspectivo e calado. } \\
\text { Gosta de usar o computador e jogar } \\
\text { baralho em Braille. }\end{array}$ & $\begin{array}{l}\text { Tornou-se extrovertido e aberto a participação nas oficinas, } \\
\text { além de demostrar uma capacidade de memória muito boa. Sua } \\
\text { escrita e leitura também apresentaram avanços significativos, } \\
\text { tanto na correção da escrita como na fluência na leitura }\end{array}$ \\
\hline
\end{tabular}

\section{Discussão e Resultados}

Conhecer o universo da criança cega, no que respeita aos processos de leitura e escrita foi o desafio perseguido durante a realização dessa pesquisa, que a despeito do número limitado de participantes permitiu lançar algumas luzes sobre o intrincado fenômeno da deficiência visual.

Assim, o primeiro dado que chama à atenção é a necessidade de formação docente para o exercício de suas funções. Foi possível constatar que a professora da sala não possui uma formação nas especificidades para o trabalho com a leitura e escrita no Sistema Braille, ou seja, falta a ela a compreensão e saberes de que a criança com cegueira tem a necessidade da leitura de textos diversos e que esse trabalho deve ter uma sequência lógica e não ser aleatório ou planejado por alguém que desconhece a criança, conforme Cunha e Enumo (2010) ressaltam de que a fala e a linguagem para a criança com deficiência visual são de fundamental importância, pois trata-se de um meio de controle do ambiente que está fora de seu alcance.

Acreditamos que o aprendizado da leitura e da escrita no sistema Braille não deve ter seu início quando a criança vai para a escola e sim desde o diagnóstico, no caso de bebês e na estimulação sensorial e visual. Isso se justifica, pois a criança vidente, desde o seu nascimento, é exposta a textos escritos de diversas formas e em vários lugares, a criança cega, salvo em alguns casos, tem contato com o Braille somente na fase da alfabetização. De acordo com
Batista (1997), os pais não compreendem adequadamente o que é a deficiência visual do filho e os reais limites e possibilidades de aprendizagem da criança. Um dos aspectos do presente trabalho foi a entrevista com as mães com o intuito de conhecer de que forma as crianças tomaram contato com o Braille e, se a família também tinha conhecimento do sistema para auxiliar as crianças em suas tarefas escolares e na leitura de textos diversos.

De posse das respostas das mães foi possível pensar em um trabalho de orientação daquelas que levam seus filhos que ainda não estão em idade escolar, para os atendimentos na instituição, para que elas possam estimulá-las desde bebês, visto que serão usuárias do sistema de leitura e escrita Braille.

A criança cega não é uma criança que se desenvolveu de forma diferente das outras, mas ela tem necessidades específicas que precisam ser atendidas (Vygotsky, 1997). Uma dessas necessidades é a aprendizagem da leitura e da escrita pelo Sistema Braille, pois a apropriação desse sistema é o caminho para seu desenvolvimento acadêmico e pessoal. Além dos aspectos motores a serem desenvolvidos pela criança para a utilização dos instrumentos como a reglete ou a máquina Braille, ela precisa desenvolver sua autonomia na escrita e a compreensão da leitura.

Durante as oficinas as crianças demonstraram que tem um conhecimento de mundo, que não é explorado em sala. Sua desenvoltura para a leitura após o conhecimento do texto e apropriação do vocabulário, se deu por meio de uma 
sequência de atividades encadeadas e que tinham o objetivo de levar a criança a ler com fluência e escrever corretamente.

Os critérios de mediação considerados universais (Klein, 1996) foram de fundamental importância para a elevação da autoestima das crianças, bem como desenvolver e consolidar o sentimento de competência na realização das atividades propostas. O critério de regulação e controle do comportamento, segundo Fonseca (1996), muito mais do que extinguir comportamentos inadequados, é um critério que demonstra a importância da modificação dos comportamentos para que as crianças possam realizar suas atividades adequadamente.

No critério de transcendência Fonseca (1996) corrobora o que já colocamos anteriormente, a importância de ouvir o que a criança traz de seu mundo, de suas experiências e que o conteúdo trabalhado faz com que aflore, enriquecendo o trabalho em sala. Para isso, segundo Kozulim (apud Gomes, 2000) os diversos instrumentos psicológicos, como a leitura, a escrita e as atividades numérica, lógicas e simbólicas devem ser bem mediados pelo professor e isso só se dá por meio de uma formação adequada.

Para que a criança cega se aproprie da escrita e da leitura pelo sistema Braille, além do trabalho de desenvolvimento da coordenação motora fina é preciso que o planejamento das atividades seja organizado de forma sequenciada, para que as estratégias propostas contribuam para a sequência de intervenções necessárias. Essas são as que permitem à memória da criança cega armazenar as informações por meio do processo de codificação, armazenamento e recuperação (Gazzaniga \& Heatherton, 2005)

O trabalho com a memória, uma das funções superiores, a qual Vigotski se referiu, é, juntamente com a audição e a fala, o caminho de aprendizagem da criança cega. Portanto, quando se estabelecem atividades aleatórias, sem um foco, uma intencionalidade não há registro significativo para a criança, conforme pudemos confirmar ao longo das oficinas realizadas para esta pesquisa.

A forma como as oficinas foram elaboradas permitiu que as crianças trabalhassem a audição, ao ouvir a história, a leitura por parte dos colegas e da pesquisadora. Permitiu, também, que escrevessem as palavras e trechos a partir da leitura da história e dos textos pelo Sistema Braille e tiveram oportunidades de se colocar expressando suas opiniões, impressões, sentimentos e críticas oralmente. Além disso, o trabalho permitiu que elas transcendessem (Fonseca, 1996) contexto presente da oficina e trouxessem fatos e acontecimentos do passado, além de antecipar situações pela informação apresentada. Esses aspectos colaboraram na elaboração de mapas mentais, permitiram que elas se apropriassem do vocabulário e a partir dessas aquisições desenvolvessem a leitura e a escrita. Embora existam críticas quanto à repetição, a criança cega depende dela, mas não uma repetição automática e sim uma sequência de atividades significativas, com intencionalidade para que a criança possa ter tempo de processar a informação e aprender.
A utilização de signos em nossa comunicação, que é balizada pela fala e pelos recursos de linguagem que utilizamos permite que, dentro do espaço escolar, onde ocorre, a aquisição do que Vygotsky (1991) denominou de conceitos científicos e que o aprendizado desses conceitos, bem como os que ele chamou de leigos - aqueles que a criança traz com ela - e o desenvolvimento estão inter-relacionados.

Durante as oficinas as crianças demonstraram maior facilidade para a leitura de palavras e trechos após o trabaIho da leitura do texto. O vocabulário se tornou significativo para elas, pois existia um contexto ao qual ele pertencia, que passou a fazer parte de sua memória e também do imaginário, uma vez que o tema trabalhado foi uma história infantil.

O trabalho de mediação nas oficinas, como já dito anteriormente, é constante, pois a criança cega depende do mediador o tempo todo, de acordo com Feuerstein e cols. (2010), a mediação deve estabelecer o uso adequado das palavras e a significação de símbolos e representações que são colocadas para o mediado, no caso o aluno.

Sendo assim, a sistematização das atividades de leitura e escrita no sistema Braille desenvolvidas provocaram nas crianças uma modificação em suas formas de encarar a leitura e a escrita como algo mecânico e sem significado. Cada uma a sua maneira, e isso pode-se verificar pela sondagem final, compreendeu que o Braille é um caminho para conhecer o mundo.

Dessa forma, a Experiência da Aprendizagem Mediada, por meio dos cinco critério trabalhados nas oficinas corrobora o que Feuerstein e cols. (2010) afirma sobre a questão de que acreditar envolve a fé (crença), a crença no potencial de desenvolvimento e capacidade de modificabilidade do aluno. Sua teoria Modificabilidade Cognitiva Estrutural (MCE) tem como primeira premissa que todo ser humano é modificável. Para que essa modificabilidade se dê no trabalho com as crianças cegas é preciso que o mediador compreenda suas necessidades e planeje seu trabalho para atingir um objetivo alcançável por elas.

Feuerstein e cols. (2010) utiliza o conceito de Modificabilidade Cognitiva Estrutural (MCE), em substituição às concepções tradicionais de inteligência, para as quais é algo inato e imutável. Para ele, a inteligência é uma força que direciona o organismo para se modificar e modificar a estrutura do pensamento e reação para responder às necessidades que aparecem.

A construção de significados deve ser trabalhada, de acordo com Feuerstein e cols. (2010), com a elaboração de valores e códigos culturais (linguagem). A mediação se dá quando se estabelece o uso adequado das palavras e a significação de símbolos e representações que são colocadas para o mediado, no caso o aluno. O mediador(professor) introduz problematizando, conceitos e significados, procedimento que colaborará para que o mediado(aluno) compreenda a realidade dada a partir de sua leitura de mundo, que por sua vez é elaborada por sentidos e significados que ele dá aos estímulos de sua realidade objetiva. 


\section{Considerações Finais}

O presente trabalho teve como objetivo construir e avaliar uma proposta de intervenção mediacional por meio de oficinas de leitura e escrita no Sistema Braille. A proposta está fundamentada nos conceitos de Vigotski sobre a defectologia, na abordagem relativa à Experiência da Aprendizagem Mediada - EAMe, em especial, pelos critérios mediacionais preconizados por Klein (1996).

Considerando a importância do Sistema Braille de leitura e escrita para as crianças cegas para sua vida acadêmica e pessoal, as atividades desenvolvidas foram voltadas para essa necessidade. Desse modo, foi possível perceber o quão importante é a participação da família, já que é o primeiro ambiente que a criança cega tem como referência de mundo.

Vale destacar que a entrevista com a professora e a observação da dinâmica da sala permitiu evidenciar a restrita autonomia docente, uma vez que os materiais são preparados pela supervisora, que não acompanhava as crianças em sala. Os temas são escolhidos aleatoriamente e as atividades descontextualizadas, impedindo uma apropriação mais adequada do vocabulário.

É importante ressaltar que a apropriação do conhecimento de mundo por uma criança cega passa pela mediação constante do mediador, seja ele o pai, a mãe, o professor etc. Nesse sentido, não há como exigir de uma criança com deficiência visual o estabelecimento de uma relação com um objeto, independente de sua natureza, que não passe pela descrição e pela visão de um vidente. Portanto, a proposta desenvolvida nas oficinas foi justamente a de construir para as crianças cegas participantes, uma rede significativa e uma relação entre leitura e escrita.

Finalizando, deve-se destacar que, em virtude das limitações de tempo, inerentes à própria pesquisa, não foi possível constatar modificações profundas no processo de leitura e escrita das crianças, mas apontou para um caminho possível, que é a sistematização do trabalho junto ao Sistema Braille. Assim, é importante que a proposta seja ampliada e mais bem pesquisada, sendo desejável o estabelecimento de uma formação docente que contemple aspectos inerentes ao planejamento e desenvolvimento de atividades significativas para as crianças, bem como a orientação das famílias.

\section{Referências}

Amiralian, M.L.T.M . (1997). Compreendendo o Cego: uma visão psicanalítica da cegueira por meio de desenhos-estórias. São Paulo: Casa do Psicólogo.

Batista, C.G. (1997). Intervenção na deficiência visual: Variáveis orgânicas e ambientais. Em Sociedade Brasileira de Psicologia (Org.), Anais da XXVII Reunião Anual da Sociedade Brasileira de Psicologia (p.28). Ribeirão Preto: SBP.
Cunha, A.C.B. \& Enumo, R.F. (2010). Mediação Materna no Desenvolvimento Cognitivo da Criança com Deficiência Visual. Curitiba: Juruá.

Feuerstein, R., Feuerstein, R.S., \& Falik, L.H. (2010). Além da Inteligência. Aprendizagem mediada e a capacidade de mudança do cérebro. Petrópolis: Vozes.

Fonseca, V. (1996). Aprender a Aprender: A educabilidade Cognitiva. Porto Alegre: Artmed.

Gazzaniga, M.S. \& Heatherton, T. F. (2005). Ciência Psicológica. Mente, Cérebro e Comportamento. Porto Alegre: Artmed.

Gomes, C. M.A.(2002) Feuerstein e a Construção Mediada do Conhecimento. Porto Alegre: Artmed

Klein, P.S. (1996). Early Intervention. Cross-cultural Experiences with a Mediational Approach. New York. Garland Publishers, 1996.

Luria, A.R. (1983). Fundamentos de neuropsicologia. São Paulo: Edusp.

Oliveira, V.B.O \& Bomtempo, E. (2009). O processo lúdico e a formação da identidade social e cultural. Em M. L. T. M. Amiralian (Org.), Deficiência Visual: perspectivas na contemporaneidade (pp.117-129). São Paulo. Vetor Editora.

Vectore, C. (2010). Mediação e Desenvolvimento: alguns apontamentos. Material elaborado para o curso de Capacitação de Educadores a Distância, Universidade Federal de Uberlândia, Uberlândia, MG.

Vygotsky, L.S. (1991). A formação social da mente. Rio de Janeiro: Martins Fontes.

Vygotsky, L.S. (1997). Fundamentos da Defectologia. Obras Escogidas. Volume $\mathrm{V}\left(2^{\mathrm{a}}\right.$ ed.). Havana: Editorial Pueblo y Educación.

Vygotsky, L.S. Luria, A.R., \& Leontiev, A.N. (2006). Linguagem, Desenvolvimento e aprendizagem (10 $10^{\mathrm{a}}$ ed.). São Paulo: Ícone.

Recebido em: 22 de agosto de 2016 Aprovado em: 13 de abril de 2017 


\section{Sobre as autoras}

Ana Maria Pereira Dionísio (anamariadionisio@yahoo.com.br)

Mestre em Psicologia pelo Instituto de Psicologia da Universidade Federal de Uberlândia. Doutoranda em Educação pela Faculdade de Educação da Universidade Federal de Uberlândia.

Celia Vectore (cvectore@gmail.com)

Professora Titular. Docente do Programa de Pós-Graduação em Psicologia da Universidade Federal de Uberlândia 